\title{
Complete DNA sequences of the plastid genomes of two parasitic flowering plant species, Cuscuta reflexa and Cuscuta gronovii Helena T Funk ${ }^{1}$, Sabine Berg${ }^{2}$, Karin Krupinska ${ }^{2}$, Uwe G Maier ${ }^{1}$ and Kirsten Krause*2,3
}

Address: ${ }^{1}$ Department of Cell Biology, Philipps-University Marburg, Karl-von-Frisch-Str., D-35032 Marburg, Germany, ${ }^{2}$ Botanisches Institut, Christian-Albrechts-Universität Kiel, Olshausenstr. 40, D-24098 Kiel, Germany and 3'Institutt for Biologi, Universitetet i Tromsø, 9037 Tromsø, Norway

Email: Helena T Funk - helena.funk@staff.uni-marburg.de; Sabine Berg - s.berg@micro-scope.de; Karin Krupinska - kkrupinska@bot.uni-kiel.de; Uwe G Maier - maier@staff.uni-marburg.de; Kirsten Krause* - kirsten.krause@ib.uit.no

* Corresponding author

Published: 22 August 2007

BMC Plant Biology 2007, 7:45 doi:10.1 I86/147|-2229-7-45
Received: 22 March 2007

Accepted: 22 August 2007

This article is available from: http://www.biomedcentral.com/I47I-2229/7/45

(C) 2007 Funk et al; licensee BioMed Central Ltd.

This is an Open Access article distributed under the terms of the Creative Commons Attribution License (http://creativecommons.org/licenses/by/2.0), which permits unrestricted use, distribution, and reproduction in any medium, provided the original work is properly cited.

\begin{abstract}
Background: The holoparasitic plant genus Cuscuta comprises species with photosynthetic capacity and functional chloroplasts as well as achlorophyllous and intermediate forms with restricted photosynthetic activity and degenerated chloroplasts. Previous data indicated significant differences with respect to the plastid genome coding capacity in different Cuscuta species that could correlate with their photosynthetic activity. In order to shed light on the molecular changes accompanying the parasitic lifestyle, we sequenced the plastid chromosomes of the two species Cuscuta reflexa and Cuscuta gronovii. Both species are capable of performing photosynthesis, albeit with varying efficiencies. Together with the plastid genome of Epifagus virginiana, an achlorophyllous parasitic plant whose plastid genome has been sequenced, these species represent a series of progression towards total dependency on the host plant, ranging from reduced levels of photosynthesis in $C$. reflexa to a restricted photosynthetic activity and degenerated chloroplasts in $C$. gronovii to an achlorophyllous state in $E$. virginiana.
\end{abstract}

Results: The newly sequenced plastid genomes of $C$. reflexa and $C$. gronovii reveal that the chromosome structures are generally very similar to that of non-parasitic plants, although a number of species-specific insertions, deletions (indels) and sequence inversions were identified. However, we observed a gradual adaptation of the plastid genome to the different degrees of parasitism. The changes are particularly evident in $C$. gronovii and include (a) the parallel losses of genes for the subunits of the plastid-encoded RNA polymerase and the corresponding promoters from the plastid genome, (b) the first documented loss of the gene for a putative splicing factor, MatK, from the plastid genome and (c) a significant reduction of RNA editing.

Conclusion: Overall, the comparative genomic analysis of plastid DNA from parasitic plants indicates a bias towards a simplification of the plastid gene expression machinery as a consequence of an increasing dependency on the host plant. A tentative assignment of the successive events in the adaptation of the plastid genomes to parasitism can be inferred from the current data set. This includes (I) a loss of non-coding regions in photosynthetic Cuscuta species that has resulted in a condensation of the plastid genome, (2) the simplification of plastid gene expression in species with largely impaired photosynthetic capacity and (3) the deletion of a significant part of the genetic information, including the information for the photosynthetic apparatus, in non-photosynthetic parasitic plants. 


\section{Background}

Parasitism among land plants has evolved independently in a variety of angiosperm families. Although knowledge of their biology is still rudimentary and limited to a relatively small number of species, it has nevertheless become apparent that a great diversity exists with respect to the anatomical and physiological adaptation to a parasitic lifestyle and the nutritional dependence on the host plants [1].

The parasitic genus Cuscuta comprises a range of species with different degrees of adaptation to the parasitic lifestyle. While all species have in common that they contain neither leaves nor roots and obtain both organic and inorganic nutrients in addition to water from their host plant through haustoria, there is some variation with respect to the structure and function of the plastids. While in some species thylakoids and even grana stacks are still present and the accumulation of photosynthetic pigments has been observed, many of the Cuscuta species contain plastids with a strongly reduced thylakoid system [2]. These species accumulate comparatively small amounts of chlorophyll. The chlorophyll content and photosynthetic activity are influenced by external factors such as nutrient supply, light intensity and the host plant species $[2,3]$. However, the net $\mathrm{CO}_{2}$ fixation rate never exceeds the compensation point $[1,2,4]$ such that all Cuscuta species are placed within the group of holoparasitic plants.

Loss of photosynthesis may directly influence the gene content of the plastid genome in parasitic plants. While no comprehensive effort has so far been undertaken to identify nuclear-encoded plastid proteins in Cuscuta or other parasitic plants, the plastid genome and its coding capacity has been under investigation in a number of parasitic plants. Here, losses of genes have been reported for several species, including Cuscuta reflexa [5-7], Conopholis americana [8], Orobanche hederae [9] and Epifagus virginiana [10]. Especially in the case of Cuscuta, where photosynthesis activity ranges from reduced levels to a nonphotosynthetic status [2], differential gene losses from the plastid genome must be expected. Under the assumption that a correlation exists between genome structure and gene content, first hints for genomic adaptations to holoparasitism were seen in hybridization studies on Cuscuta plastid DNA, in which differences in the genome sizes correlate with photosynthetic capacity $[11,12]$.

Compared to plastid gene expression in green algae, land plant plastids exhibit several differences. These include the transcription mechanisms of plastid genes, intron splicing as well as RNA editing. Contrary to algae, land plant plastid chromosomes are transcribed by two different RNA polymerases. Beside the plastid-encoded RNA polymerase (PEP) that is thought to be mainly responsi- ble for the expression of the components of the photosynthetic apparatus and that is present in algae as well, a nuclear-encoded RNA polymerase (NEP) additionally acts in land plant plastids. The main activity of the NEP seems to be the expression of housekeeping genes $[13,14]$.

Introns and RNA editing are common in land plant chloroplasts which distinguish them further from green algal chloroplasts. Typically, one group I intron and about 20 group II introns are present in the plastid genome of photosynthetic land plants [15]. Chloroplast RNA editing of land plants restores conserved amino acid residues at highly specific sites by a C-to-U conversion at the mRNA level [16] and occurs usually at functionally relevant sites [17-21]. The number and location of the editing sites, the so-called editotype [22], varies between different species, but - with the exception of Marchantia polymorpha [23] at least approximately 30 editing sites per plastid chromosome were detected in higher land plants.

Presently, complete plastid genome sequences are available from a huge variety of different organisms [24]. However, the only one for a parasitic plant is that of the achlorophyllous root parasite E. virginiana [10]. This genome is presently the smallest known plastid genome of land plants with a size of $70 \mathrm{~kb}$. Despite this reduction in size several typical features for plastid genomes were retained, e.g. the possession of introns and the necessity of RNA editing [25]. Others, such as the possession of a plastid-encoded RNA polymerase (PEP), are absent.

In order to improve knowledge about the capacities of parasitic plants, we sequenced the plastid genomes of $C$. reflexa and C. gronovii. Together with the plastid genome of Epifagus, this has allowed a comparative analysis of the molecular changes that mark the progression towards holoparasitism and an adaptation to a parasitic lifestyle in land plants.

\section{Results and discussion}

\section{Size and structure of plastid chromosomes}

Sequence data of entire plastid chromosomes were obtained for C. reflexa [EMBL: AM711640] and C. gronovii [EMBL: AM711639] and compared to two selected known plastid genomes, that of the Solanaceae Nicotiana tabacum $[26,27]$ and that of Epifagus virginiana [10]. Thus, our data set contains the plastid genome sequences of three parasitic plants and that of $N$. tabacum. The latter species was chosen as non-parasitic reference because it belongs to the same order as Cuscuta, Solanales, and its plastid genome has been thoroughly analyzed which is why it has served as reference plant previously $[11,12]$.

In terms of overall size, the plastid chromosome of C. reflexa was found to contain 121,521 bp which is very close 


\section{Figure I}

Gene Maps of the plastid chromosomes of Cuscuta reflexa and Cuscuta gronovii. Genes shown on the right hand side are transcribed top down and genes on the left hand side bottom up. The large single copy region (LSC) and the small single copy region (SSC) are separated by two inverted repeats $\left(I R_{A}\right.$ and $\left.I R_{B}\right)$. Asterisks indicate intron containing genes. Pseudogenes are marked by $\Psi$. Dashed lines indicate the inverted regions between $C$. reflexa and $C$. gronovii.

to the $122 \mathrm{kbp}$ that were estimated based on the extent of hybridization to tobacco [12]. In contrast, the plastid chromosome of C. gronovii consists of only 86,744 bp (Table 1) whereas the plastid chromosome size of E. virginiana with $70,028 \mathrm{bp}$ is still significantly smaller and remains the smallest sequenced plastid genome of higher land plants known so far [10]. N. tabacum, in comparison, possesses a plastid chromosome consisting of 155,939 bp (Table 1) [26,27]. As expected, the genome size reflects the declining dependency on one of the major benefits of plastids, photosynthesis. In comparison with E. virginiana, an additional $17 \mathrm{kbp}$ of plastid genome sequence was preserved in C. gronovii. This difference is mainly caused by genes encoding the subunits needed for the photosynthetic apparatus, which are missing in E. virginiana.

The plastid chromosomes from both Cuscuta species show a typical organization with a large single copy region (LSC) and a small single copy region (SSC) separated by two inverted repeat regions $\left(\mathrm{IR}_{\mathrm{A}}\right.$ and $\left.\mathrm{IR}_{\mathrm{B}}\right)$ (Table 1; Fig. 1 ). It should be noted that in contrast to the predicted overall size [12], the predicted sizes of the individual regions of C. reflexa were significantly less accurate, with the LSC and SSC being some $21 \mathrm{kbp}$ and $3.5 \mathrm{kbp}$, respectively, larger

Table I: Properties of the plastid genomes of Nicotiana tabacum, Cuscuta reflexa, Cuscuta gronovii and Epifagus virginiana

\begin{tabular}{|c|c|c|c|c|}
\hline & N. tabacum & C. reflexa & C. gronovii & E. virginiana \\
\hline total [bp] & 155,939 & $|2|, 52 \mid$ & 86,744 & 70,028 \\
\hline $\begin{array}{l}\text { LSC [bp] } \\
\text { (\% of total) }\end{array}$ & $\begin{array}{l}86,686 \\
(55.6)\end{array}$ & $\begin{array}{c}79,468 \\
(65.4)\end{array}$ & $\begin{array}{l}50,973 \\
(58.8)\end{array}$ & $\begin{array}{l}19,799 \\
(28.3)\end{array}$ \\
\hline $\begin{array}{l}\text { SSC [bp] } \\
\text { (\% of total) }\end{array}$ & $\begin{array}{l}|8,57| \\
(11.9)\end{array}$ & $8,57 \mid(7.0)$ & $7,063(8.1)$ & 4,759 (6.8) \\
\hline $\begin{array}{l}\text { IR }[\mathrm{bp}] \text { (\% of } \\
\text { total) }\end{array}$ & $\begin{array}{l}25,34 \mid \\
(16.3)\end{array}$ & $\begin{array}{l}|6,74| \\
(13.8)\end{array}$ & $\begin{array}{l}14,354 \\
(16.6)\end{array}$ & $\begin{array}{l}22,735 \\
(32.5)\end{array}$ \\
\hline$\%$ coding & $49 \%$ & $69 \%$ & $75 \%$ & $43 \%$ \\
\hline $\begin{array}{l}\text { number of } \\
\text { genes }\end{array}$ & 113 & 98 & 86 & 40 \\
\hline $\begin{array}{l}\text { number of } \\
\text { genes with } \\
\text { introns } \\
\text { (with } 2 \\
\text { introns) }\end{array}$ & $18(3)$ & $12(3)$ & $5(1)$ & $4(2)$ \\
\hline
\end{tabular}

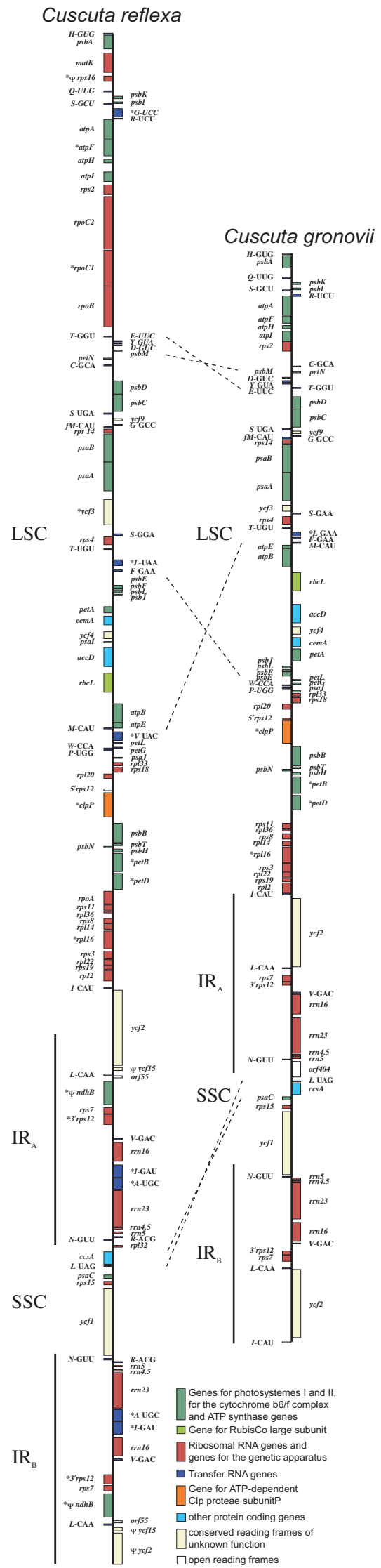


than anticipated, while the inverted repeat is roughly 12 kbp smaller than reported by these authors. These substantial deviations demonstrate the value of the more tedious sequence analysis over hybridization analysis.

Interestingly, the $\mathrm{IR}_{\mathrm{A}}$-LSC junction $\left(\mathrm{J}_{\mathrm{LA}}\right)$ in C. reflexa was found to be within the $y c f 2$ gene. Due to this reduction of the inverted repeat there is only one copy of $r p l 2$, trnI-cau and one complete $y c f 2$ gene. Compared to tobacco and other plastid genomes of higher land plants, C. reflexa exhibits three sequence inversions within the plastid chromosome, two in the large single copy region comprising $\sim 2 \mathrm{~kb}$ and $\sim 13 \mathrm{~kb}$ in length, and one of $\sim 1.5 \mathrm{~kb}$ length in the small single copy region. None of these inversions were detected in either C. gronovii or E. virginiana (Fig. 1). The $13 \mathrm{~kb}$ inversion was already hypothesized by Haberhausen et al. in 1992 [5]. The same inversion was also observed in another species of the subgenus Monogyna, C. japonica, but is absent from the subgenera Grammica and Cuscuta [28]. This is consistent with our findings for $C$. gronovii, which belongs to the subgenus Grammica. The two other inversions were also identified only in the plastid genome of $C$. reflexa and may thus imply that the inversions are unrelated to parasitism. For both Cuscuta species, overlapping PCR products indicate the existence of a circular form of the plastid chromosomes.

\section{Coding potential}

Both plastid chromosomes of Cuscuta encode a reduced amount of genes compared to that of N. tabacum (Table 2 ). Among the genes that are missing in C. reflexa are the $n d h$ genes that encode for the subunits of the NADH dehydrogenase complex required for chlororespiration. Besides the loss of these genes, the genes infA, trnK-uuu and the orf350 were completely eliminated from the plastid genome, and two ribosomal protein genes ( $r p l 23$, rps16) as well as $y c f 15$ were retained only as pseudogenes (Table 2). With the exception of orf404 (homologous to the tobacco orf350), all genes and pseudogenes mentioned above were also lost in C. gronovii. Further specific gene losses on the plastid genome of $C$. gronovii have been detected for $p s a I, m a t K, t r n V$-uac, rpl32 and the rpo genes. In addition, there are two tRNA genes whose sequences were completely eliminated from the plastid DNA, and four tRNA genes (trnA-ugc, trnG-ucc, trnI-gau, trnR-agc) that have remained only as pseudogenes (Table 2 ). The lack of some tRNA genes on the plastid genome of the Cuscuta species raised the question whether the codon usage was altered in response to the tRNA losses. We therefore performed an analysis of the codon usages in both species. The typically 30 tRNA genes, which are encoded on a ptDNA, are considered to be sufficient to read all 61 sense codons of chloroplast genes [29]. Surprisingly, all 61 sense codons were found in the coding regions of the genes in both Cuscuta species and seem to be used, moreover, in a similar proportion as in non-parasitic plants that possess a 'full' plastid tRNA set (Table 3). For example, $77.8 \%$ of the lysine residues in tobacco are encoded by the codon AAA, for which tRNA trnK-uuu is absent from both Cuscuta ptDNAs. For E. virginiana, an import of cytosolic tRNAs into the chloroplast was suggested [30,31] which probably must be assumed for Cuscuta as well. The mechanism is supposed to be based on the same co-import with protein factors that seems to be responsible for the import of cytosolic tRNAs into mitochondria [32]. However, it is unclear why some tRNAs were retained, whereas others were lost. In this context, it is perhaps noteworthy that the subset of tRNAs conserved in the plastid genomes of parasitic plant plastids (including Cuscuta) shows a remarkable overlap with the set of mitochondrial encoded tRNAs for which no import has ever been observed [see also [33]].

It is apparent that many gene losses from the Cuscuta plastid genomes concern genes for the gene expression apparatus such as ribosomal protein genes and tRNA genes but affect also a few genes involved in photosynthetic carbon fixation (ndh, psaI in C. gronovii). The deletion of genes that are typically encoded by the plastid genome in land plants is, however, not a feature that is characteristic for plastid genomes of parasitic plants alone. In Pinus thunbergii, for example, the ndh genes are not encoded by the plastid genome either [34], while other photosynthetic lineages have lost the rpl23 and rps16 genes from their plastid DNA. Similar to the tRNA genes, it can, at present, not be ruled out that some or all of these plastid genes have been transferred to the nuclear genome and are imported into the plastids from the cytosol. In fact, this seems to be the case in some non-parasitic plants, for example, with the ribosomal proteins $r p l 23$ and $r p s 16$ which seem to be imported from the nucleus [35-37]. The same situation is discussed for ribosomal proteins of Epifagus [31] and is also likely for Cuscuta since the detection of photosynthesis-related proteins suggests that plastid translation is functional [2]. So far, a complete gene loss can only be safely assumed for the rpo genes of $C$. gronovii where their absence has been confirmed by a genomewide hybridization [38].

\section{Promoter structures}

In several parasitic plant species, among them $C$. gronovii and E. virginiana, the rpo genes coding for the PEP-subunits were either truncated or totally deleted from the plastid genome by natural evolution [38-41]. As mentioned above, the existence of a functional nuclear complement of these genes is very unlikely in $C$. gronovii. Transcription in these plastids, therefore, has to rely on an imported NEP or a so far unknown nuclear-encoded RNA polymerase different from that known from angiosperms. In E. virginiana all PEP dependent photosynthesis-related genes 
Table 2: Gene content of Cuscuta reflexa and Cuscuta gronovii ptDNA compared to Nicotiana tabacum and Epifagus virginiana

\begin{tabular}{|c|c|c|c|c|c|c|c|c|c|c|c|c|c|c|}
\hline \multicolumn{5}{|c|}{$\begin{array}{l}\text { photosynthetic and chlororespiratory } \\
\text { genes }\end{array}$} & \multicolumn{5}{|c|}{ ribosomal RNA genes } & \multicolumn{5}{|c|}{ transfer RNA genes } \\
\hline & $\mathrm{Nt}$ & $\mathrm{Cr}$ & $\mathrm{Cg}$ & Ev & & $\mathrm{Nt}$ & $\mathrm{Cr}$ & $\mathrm{Cg}$ & Ev & & $\mathrm{Nt}$ & $\mathrm{Cr}$ & $\mathrm{Cg}$ & EV \\
\hline atpA & + & + & + & $\Psi$ & $r n / 6$ & + & + & + & + & trnA-ugc & + & + & $\Psi$ & $\Psi$ \\
\hline $\operatorname{atpB}$ & + & + & + & $\Psi$ & $r r n 23$ & + & + & + & + & $\operatorname{trnC}$-gca & + & + & + & $\Psi$ \\
\hline $\operatorname{atp} E$ & + & + & + & - & $r r n 4.5$ & + & + & + & + & trnD-guc & + & + & + & + \\
\hline atpF & + & + & + & - & $r r n 5$ & + & + & + & + & trnE-uuc & + & + & + & + \\
\hline atpH & + & + & + & - & & & & & & trnF-gaa & + & + & + & + \\
\hline atpl & + & + & + & - & & & & & & $\operatorname{trnfM-cau}$ & + & + & + & + \\
\hline ndhA & + & - & - & - & & & & & & $\operatorname{trnG-gcc}$ & + & + & + & - \\
\hline$n d h B$ & + & $\Psi$ & - & $\Psi$ & \multicolumn{5}{|c|}{ RNA polymerase and maturase genes } & trnG-ucc & + & + & $\Psi$ & - \\
\hline$n d h C$ & + & - & - & - & & & & & & trnH-gug & + & + & + & + \\
\hline$n d h D$ & + & - & - & - & & & & & & trnl-cau & + & + & + & + \\
\hline$n d h E$ & + & - & - & - & & $\mathrm{Nt}$ & $\mathrm{Cr}$ & $\mathrm{Cg}$ & Ev & trnl-gau & + & + & $\Psi$ & $\Psi$ \\
\hline$n d h F$ & + & - & - & - & matK & + & + & - & + & trnK-uuu & + & - & - & - \\
\hline$n d h G$ & + & - & - & - & $r p o A$ & + & + & - & $\Psi$ & trnL-caa & + & + & + & + \\
\hline$n d h H$ & + & - & - & - & rpoB & + & + & - & - & trnL-uaa & + & + & + & - \\
\hline$n d h l$ & + & - & - & - & rpoCl & + & + & - & - & trnL-uag & + & + & + & + \\
\hline ndhJ & + & - & - & - & rpoc2 & + & + & - & - & trnM-cau & + & + & + & + \\
\hline ndhK & + & - & - & - & & & & & & trnN-guu & + & + & + & + \\
\hline petA & + & + & + & - & & & & & & trnP-ugg & + & + & + & + \\
\hline petB & + & + & + & - & \multicolumn{5}{|c|}{$\begin{array}{c}\text { ribosomal protein and initiation factor } \\
\text { genes }\end{array}$} & trnQ-uug & + & + & + & + \\
\hline petD & + & + & + & - & & & & & & trnR-acg & + & + & $\Psi$ & + \\
\hline petG & + & + & + & - & & & & & & $\operatorname{trnR-ucu}$ & + & + & + & $\Psi$ \\
\hline petL & + & + & + & - & & $\mathrm{Nt}$ & $\mathrm{Cr}$ & $\mathrm{Cg}$ & $\mathrm{Ev}$ & $\operatorname{trnS}$-gcu & + & + & + & + \\
\hline $\operatorname{pet} N$ & + & + & + & - & $\operatorname{infA}$ & $\Psi$ & - & - & + & trnS-gga & + & + & + & $\Psi$ \\
\hline psaA & + & + & + & - & rpl/4 & + & + & + & $\Psi$ & trnS-uga & + & + & + & + \\
\hline psaB & + & + & + & - & $r p / 16$ & + & + & + & + & trnT-ggu & + & + & + & - \\
\hline psaC & + & + & + & - & $r p / 2$ & + & + & + & + & $\operatorname{trnT} T$-ugu & + & + & + & - \\
\hline psal & + & + & - & - & $r p / 20$ & + & + & + & + & trnV-gac & + & + & + & - \\
\hline psal & + & + & + & - & $r p / 22$ & + & + & + & - & trnV-uac & + & + & - & - \\
\hline$p s b A$ & + & + & + & $\Psi$ & $r p / 23$ & + & $\Psi$ & - & $\Psi$ & trnW-cca & + & + & + & + \\
\hline$p s b B$ & + & + & + & $\Psi$ & $r p / 32$ & + & + & - & - & trnY-gua & + & + & + & + \\
\hline$p s b C$ & + & + & + & - & $r p / 33$ & + & + & + & + & & & & & \\
\hline$p s b D$ & + & + & + & - & $r p / 36$ & + & + & + & + & \multicolumn{5}{|c|}{ other protein genes } \\
\hline$p s b E$ & + & + & + & - & rps II & + & + & + & + & & $\mathrm{Nt}$ & $\mathrm{Cr}$ & $\mathrm{Cg}$ & Ev \\
\hline$p s b F$ & + & + & + & - & $r p s / 2$ & + & + & + & + & $c l p P$ & + & + & + & + \\
\hline psbH & + & + & + & - & rps / 4 & + & + & + & + & $a c c D$ & + & + & + & + \\
\hline psbl & + & + & + & - & rps $/ 5$ & + & + & + & - & $y c f l$ & + & + & + & + \\
\hline psbJ & + & + & + & - & rps /6 & + & $\Psi$ & - & - & $y c f 2$ & + & + & + & + \\
\hline psbK & + & + & + & - & rps/8 & + & + & + & + & $y c \subset 3$ & + & + & + & - \\
\hline psbl & + & + & + & - & rps 19 & + & + & + & + & ycf 4 & + & + & + & - \\
\hline$p s b M$ & + & + & + & - & rps2 & + & + & + & + & ycf5 & + & + & + & - \\
\hline$p s b N$ & + & + & + & - & rps3 & + & + & + & + & ycfo & + & + & + & - \\
\hline psbT & + & + & + & - & rps 4 & + & + & + & + & ycflo & + & + & + & - \\
\hline \multirow[t]{2}{*}{$r b c L$} & + & + & + & $\Psi$ & rps7 & + & + & + & + & ycfl5 & + & $\Psi$ & $\Psi$ & $\Psi$ \\
\hline & & & & & rps8 & + & + & + & + & orf350 & + & - & + & + \\
\hline
\end{tabular}

+: gene present; -: gene deleted; pseudogenes are indicated by $\Psi$; Nt: Nicotiana tabacum; Cr: Cuscuta reflexa; Cg: Cuscuta gronovii; Ev: Epifagus virginiana 
Table 3: Codon usages for codons for which the tRNAs are not encoded on the plastid genome of Cuscuta reflexa and Cuscuta gronovii compared to Nicotiana tabacum

\begin{tabular}{lccc}
\hline Codon (amino acid) & $\mathrm{Nt}$ & $\mathrm{Cr}$ & $\mathrm{Cg}$ \\
\hline GCT (Ala) & $44,52 \%$ & $43,36 \%$ & $\mathbf{4 0 , 4 3 \%}$ \\
GGT (Gly) & $34,42 \%$ & $30,50 \%$ & $\mathbf{3 4 , 3 8 \%}$ \\
ATC (lle) & $19,72 \%$ & $17,66 \%$ & $\mathbf{1 8 , 1 0 \%}$ \\
AAA (Lys) & $77,81 \%$ & $\mathbf{7 9 , 2 1 \%}$ & $\mathbf{7 9 , 1 5 \%}$ \\
CGT (Arg) & $24,95 \%$ & $20,87 \%$ & $\mathbf{2 2 , 6 7 \%}$ \\
GTA (Val) & $38,68 \%$ & $35,87 \%$ & $\mathbf{3 1 , 0 7 \%}$ \\
\hline
\end{tabular}

Bold italic numbers indicate that the tRNA is missing on the ptDNA in the corresponding species. Nt: Nicotiana tabacum; Cr: Cuscuta reflexa; Cg: Cuscuta gronovii

were eliminated, as well. This is different in C. gronovii, which has retained the majority of photosynthesis-related genes despite the loss of the PEP. In conclusion, a nuclearencoded RNA polymerase has to be responsible for the expression of photosynthesis-related genes at levels sufficient to allow for photosynthesis [42].

In order to investigate what effects this loss of PEP had on the promoters of plastid genes in C. gronovii, the 5'-regions of five transcription units known to be transcribed by PEP in non-parasitic land plants were examined (Fig. 2). In tobacco and other photosynthetic plastids, the $p s b A$ gene is transcribed monocistronically from a single PEP promoter, which is characterized by a TATA-like sequence motif and a TGn motif between the -10 and -35 boxes [43]. While in C. reflexa this typical consensus motif is highly conserved, C. gronovii exhibits pronounced changes in the sequence leaving only the -10 box unaltered (Fig. 2A). A similar picture emerges with the unique blue-light responsive promoter (LRP) of the $p s b D / C$ operon (Fig. 2B). This promoter was shown to be activated by high-irradiance blue and UVA light, low temperature, high salt and high osmotic conditions $[44,45]$. In both Cuscuta species this promoter is, however, located closer to the translation start site than in tobacco (Fig. 2B). The promoter of $p s b K$ [46] shows changes in the - 10 and 35 box in C. gronovii and only one change in the -35 box of C. reflexa (Fig. 2D). In contrast to the three promoters controlling photosystem II genes, the promoter of the $p s a A / p s a B / r p s 14$ operon [47] is remarkably conserved not only in C. reflexa but also in C. gronovii (Fig. 2C). The atpE promoter [48] is unaltered in C. reflexa as is the -35 box in C. gronovii, whereas the -10 box shows two base changes (Fig. 2E).

It was previously shown for the $r b c L$ gene, that a shift in transcription start sites accompanied by a replacement of the typical PEP promoter has taken place [42]. The 5' region of the new transcription start site revealed striking similarities to the sequence motifs recognized by the phage-type NEP so that it can be safely assumed that this NEP has taken over $r b c L$ transcription in this species. As detailed above, the complete plastid genome sequence of C. gronovii has now revealed that other PEP-promoters seem to be significantly altered (Fig. 2), too, so that changes similar to those observed for $r b c L$ can be hypothesized and could be part of a systematic and general alteration. As a consequence of these changes, one should expect that major transcriptional regulations such as redox control [49] of the expression of the photosynthetic apparatus are no longer possible.

\section{Splicing}

The matK gene, which is coding for a putative maturase that is thought to be essential for the splicing of several

Table 4: Appearance of introns in the three parasitic plants Cuscuta reflexa, Cuscuta gronovii and Epifagus virginiana

\begin{tabular}{|c|c|c|c|c|}
\hline & Gene $(\mathrm{Nt})$ & C. reflexa & C. gronovii & E. virginiana \\
\hline \multicolumn{5}{|c|}{ group I: } \\
\hline & trnL-uaa & intron & intron & - \\
\hline \multicolumn{5}{|c|}{ group II: } \\
\hline \multirow[t]{6}{*}{ Al } & $\begin{array}{l}\text { rps / } 2 \\
\text { (intron 2) }\end{array}$ & intron & no intron & intron \\
\hline & trnl-gau & intron & $\psi$ & $\psi$ \\
\hline & $\operatorname{trn} A$-ugc & intron & $\psi$ & $\psi$ \\
\hline & trnV-uac & intron & - & - \\
\hline & trnK-uuu & - & - & - \\
\hline & $\begin{array}{l}c l p P \text { (intron } \\
2 \text { ) }\end{array}$ & intron & intron & intron \\
\hline \multirow[t]{2}{*}{$\mathrm{A} 2$} & $a t p F$ & intron & no intron & - \\
\hline & $r p / 2$ & no intron & no intron & intron \\
\hline \multirow[t]{6}{*}{ BI } & pet $B$ & intron & intron & - \\
\hline & petD & intron & intron & - \\
\hline & rps 16 & - & - & - \\
\hline & rpoCl & intron & - & - \\
\hline & $\begin{array}{l}\text { yç3 (intron } \\
2 \text { ) }\end{array}$ & intron & no intron & - \\
\hline & $\begin{array}{l}c l p P \text { (intron } \\
\text { I) }\end{array}$ & intron & intron & intron \\
\hline \multirow[t]{6}{*}{ B2 } & $\begin{array}{l}\text { rps } / 2 \\
\text { (intron I } \\
\text { trans) }\end{array}$ & intron & intron & intron \\
\hline & $r p / 16$ & intron & intron & intron \\
\hline & $n d h B$ & $\psi$ & - & $\psi$ \\
\hline & $n d h A$ & - & - & - \\
\hline & $\begin{array}{l}\text { yç3 (intron } \\
\text { I) }\end{array}$ & intron & no intron & - \\
\hline & trnG-ucc & intron & $\psi$ & - \\
\hline
\end{tabular}

All intron containing genes in $\mathrm{N}$. tabacum $(\mathrm{Nt})$ are listed. 'intron': intron containing gene; 'no intron': gene without intron; ' $\Psi$ ' indicates pseudogenes; '-': gene not present in the particular plastid chromosome a 
plastid introns [50-54], has been lost from the plastid genome of $C$. gronovii. This observation merits attention since $m a t K$ was found on all other sequenced plastid genomes, so far. Therefore, this deletion should be accompanied by changes or losses of the affected introns, unless matK was barely transferred to the nuclear genome of $C$. gronovii. The plastid chromosome of tobacco possesses a total of 21 introns in 18 genes. Only one gene possesses a group I intron while the remaining introns belong to the larger group II [15]. The group I intron was retained in both Cuscuta species while it was lost from the Epifagus ptDNA (Table 4) [10]. Group II introns are divided into group IIA and group IIB introns [15] and splicing of the group IIA introns is postulated to be dependent on the matK gene product [50-54]. From the 20 group II introns found in tobacco, eight are of the IIA type. Six of these introns were retained in C. reflexa. The two absent group IIA introns in C. reflexa are the rpl2 intron and an intron in $\operatorname{trnK}$-uuu, for which the gene is eliminated in C. reflexa. Interestingly, the matK gene, that is encoded within the trnK-uuu intron in other plastid genomes was retained and is present as a free-standing gene in C. reflexa. $C$. gronovii has retained only one group IIA intron belonging to the subgroup IIA1, namely intron 2 of $\operatorname{clpP}$ (Table 4). Surprisingly, this intron is spliced from the corresponding primary transcript despite the lack of the matK gene on the plastid genome (Fig. 3). Therefore, it may either be possible that a MatK-like protein is imported from the cytosol

Table 5: Editing sites in Cuscuta reflexa and Cuscuta gronovii

\begin{tabular}{|c|c|c|c|c|c|c|}
\hline \multirow[b]{2}{*}{ gene } & \multirow[b]{2}{*}{ pos. } & \multirow[b]{2}{*}{ cons. } & \multicolumn{2}{|c|}{ C. reflexa } & \multicolumn{2}{|c|}{ C. gronovii } \\
\hline & & & codon & & codon & \\
\hline$a c c D$ & $\begin{array}{c}258 / \\
173\end{array}$ & L & $\mathrm{t} C g$ & $S>L$ & tta & L \\
\hline atpF & 31 & L & $\mathrm{cCa}$ & $P>L$ & $\mathrm{ctt}$ & L \\
\hline \multirow[t]{2}{*}{ petB } & 140 & W & Cgg & $\mathrm{R}>\mathrm{W}$ & $\operatorname{tgg}$ & W \\
\hline & 204 & $\mathrm{~L}$ & $\mathrm{cCa}$ & $P>L$ & cta & $\mathrm{L}$ \\
\hline petL & 2 & L & $\mathrm{ctt}$ & $\mathrm{L}$ & cct & $P$ \\
\hline psbE & 72 & $S$ & Cct & $P>S$ & cct & $P$ \\
\hline psbl & I & $M$ & $\mathrm{aCg}$ & $T>M$ & $\mathrm{aCg}$ & $\mathrm{T}>\mathrm{M}$ \\
\hline rpl20 & 103 & $\mathrm{~L}$ & tca & $S$ & tca & $\mathrm{S}$ \\
\hline \multirow[t]{5}{*}{ rpoB } & 113 & $\mathrm{~L}$ & $\mathrm{tCt}$ & $\mathbf{S}>\mathbf{F}^{*}$ & \multicolumn{2}{|c|}{ not encoded } \\
\hline & 158 & L & $\mathrm{tCa}$ & $\mathbf{S}>\mathbf{L}^{*}$ & & \\
\hline & 184 & L & $\mathrm{tCa}$ & $S>L^{*}$ & & \\
\hline & 189 & L & $\mathrm{tCg}$ & $S>L$ & & \\
\hline & 667 & $\mathrm{~F}$ & $\mathrm{tCt}$ & $S>F$ & & \\
\hline rpoCl & 21 & L & $\mathrm{tCg}$ & $\mathbf{S}>\mathbf{L}^{*}$ & & \\
\hline \multirow[t]{2}{*}{ rps2 } & 45 & I & $\mathrm{aCa}$ & $\mathrm{T}>\mathrm{I}$ & $\mathrm{aCa}$ & $\mathrm{T}>\mathrm{I} *$ \\
\hline & 83 & L & tca & $S$ & gca & $A$ \\
\hline \multirow[t]{2}{*}{ rps $/ 4$} & 27 & L & $\mathrm{tCa}$ & $S>L$ & $\mathrm{tCa}$ & $\mathbf{S}>\mathbf{L}^{*}$ \\
\hline & 50 & L & $\mathrm{tCa}$ & $S>L$ & $\mathrm{tCa}$ & $S>L$ \\
\hline
\end{tabular}

'pos.': amino acid position within the gene; 'cons.': conserved amino acid at this position; upper-case ' $C$ ' indicates the editing site; bold indicates that the ratio of edited vs. unedited transcripts depends on photosynthetic activity. to splice this intron of $c l p P$ or, alternatively, that this intron does not require the matK gene product for splicing. Recently, Hattori et. al. [55] could show in the moss Physcomitrella patens, that a nuclear-encoded PPR protein is involved in the splicing process of $c l p P$. There is also one group IIA intron in $a t p F$, for which MatK and the nuclearencoded factor pCRS1 are necessary for splicing $[54,56]$. If indeed a different nuclear-encoded factor is responsible for the splicing of the intron 2 of $c l p P$, the splicing factor MatK could have been lost completely in C. gronovii in adaptation to the parasitic lifestyle. All other group IIA introns known from Epifagus or other plastid genomes were eliminated in C. gronovii irrespective of the presence of the corresponding gene (Table 4). Among the twelve group IIB introns from tobacco plastid genomes, which are spliced in a $m a t K$-independent manner, three were lost in C. reflexa and seven in C. gronovii (Table 4). The presence or absence of all introns and their splicing were confirmed by PCR and RT-PCR (data not shown).

\section{RNA editing}

To determine the editotypes of C. reflexa and C. gronovii, we first performed an in silico analysis for potential editing sites. All known editing sites in chloroplasts of higher land plants were investigated for their occurrence in C. reflexa and C. gronovii on the DNA level. All potential editing sites were then analyzed by RT-PCR and sequencing of the cDNAs (Fig. 4). The average amount of editing sites in non-parasitic higher land plants is around 30.17 potential editing sites were identified in C. reflexa, from which eleven were found to be completely edited, four are partially edited and two were found to remain unedited. Taking the gene losses in C. reflexa (ndh genes) into account, this is in the range of what one would expect and implies C. reflexa's lack of strong selection in its loss of editing sites. Interestingly, the UCA at codon position 103 in rpl20 and the TCA at codon position 83 in rps 2 remain unedited. In other species, these positions are known to be modified through RNA editing such that they encode the highly conserved amino acids. Because the position 103 in rpl20 was also found not to be edited in C. gronovii, it could be possible that the resulting isoform of Rpl20 with a serine at position 103, is specific for the genus Cuscuta. Nonetheless, it cannot be ruled out that this isoform might show an impaired functionality, which can only be tolerated due to the parasitic lifestyle of the genus Cuscuta. A different picture emerges for the rps-83 editing site. This editing site remains an unedited GCA alanine codon in C. reflexa whereas in C. gronovii a TCA codon is found instead, which is also not edited. However, even editing at this position in C. gronovii could not restore the conserved leucine. This may indicate that this normally highly conserved position is no longer conserved as a consequence of the parasitic lifestyle of Cuscuta. 
In contrast, only four out of seven potential editing sites were edited in C. gronovii, two of them are partially edited (Table 5 and Fig. 4). For three out of the four partially edited sites in C. reflexa and for one partial editing site in C. gronovii, we could observe higher editing efficiencies in photosynthetic active tissue (in the tips of the seedlings of C. reflexa and C. gronovii grown without a host plant; Fig. $4)$. In contrast to C. reflexa, C. gronovii shows a pronounced reduction of editing sites compared to other so far investigated angiosperms. On the one hand, this is the result of the loss of the rpo genes. On the other hand, the conserved amino acid is already encoded at the DNA level at four sites, namely accD-173, atpF-31, petB-140 and petB204, which makes editing superfluous. In C. gronovii, in addition to the rpl20-103 and the rps2-83 editing sites, two potential editing sites remain unedited at position 72 in $p s b E$ and position 2 in petL, which are edited in C. reflexa or already have the conserved amino acid encoded at the
DNA level. Moreover, a reduction of the editing efficiency at rps2-45 and rps14-27 can be seen in C. gronovii in comparison to C. reflexa. Thus, we speculate that in $C$. gronovii RNA editing might be diminishing with the advanced adaptation to a parasitic lifestyle.

\section{Conclusion}

In the case of phototrophic organisms, parasitism dramatically influences the plant as well as the plastid morphology as seen in the case of Cuscuta. Conversely, parasitism is not necessarily reflected by the genome of the plastids as can be observed for the two investigated plastid genomes of C. reflexa and C. gronovii. Only minor changes are obvious in the plastid genome of $C$. reflexa and the parasitic lifestyle of this plant is therefore not obvious from the structure and coding capacity of the plastid genome. Analysis of plastid gene expression has shown that the relative plastid transcript levels in $C$. reflexa

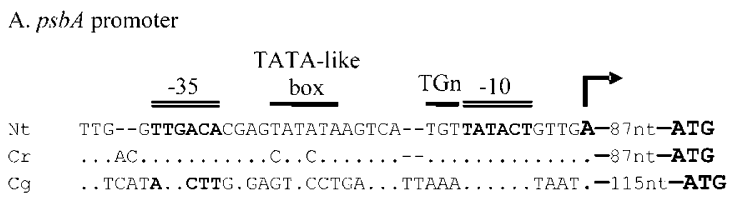

B. $p s b D$ LRP (light responsive) promoter
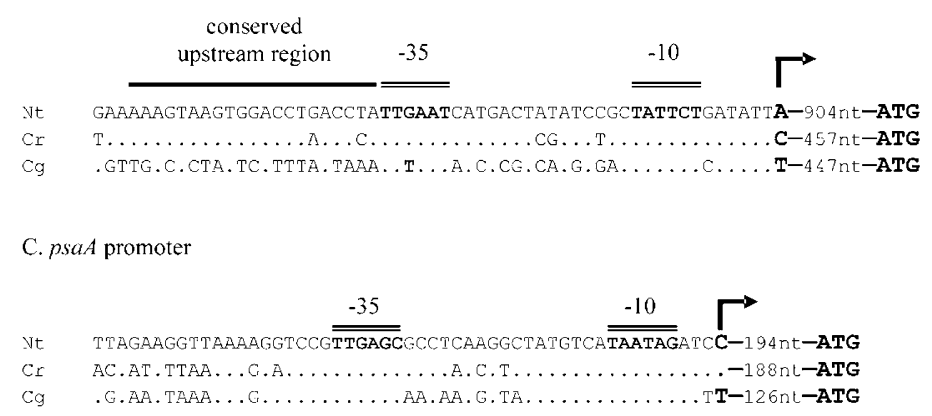

D. $p s h K$ promoter

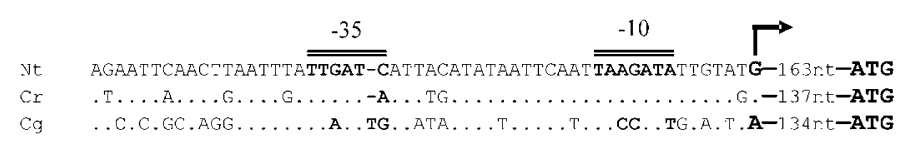

E. atpE promoter

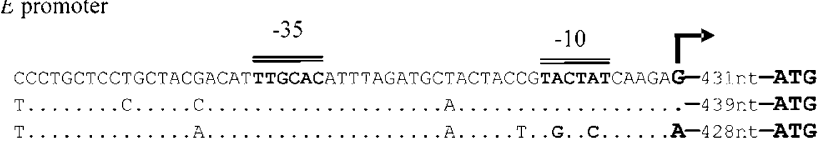

Figure 2

Comparison of promoter sequences of five PEP promoters in Nicotiana tabacum, Cuscuta reflexa and Cuscuta gronovii. Double lines indicate the consensus motifs of the -10 and -35 boxes typical of plastid PEP promoters. Other conserved regions are marked with a single black line. The distance in nucleotides between the transcription start (indicated by a rightward arrow) and the translation start (ATG) is given. Black dots represent residues that are identical to the nucleotides of N. tabacum shown at the top. 

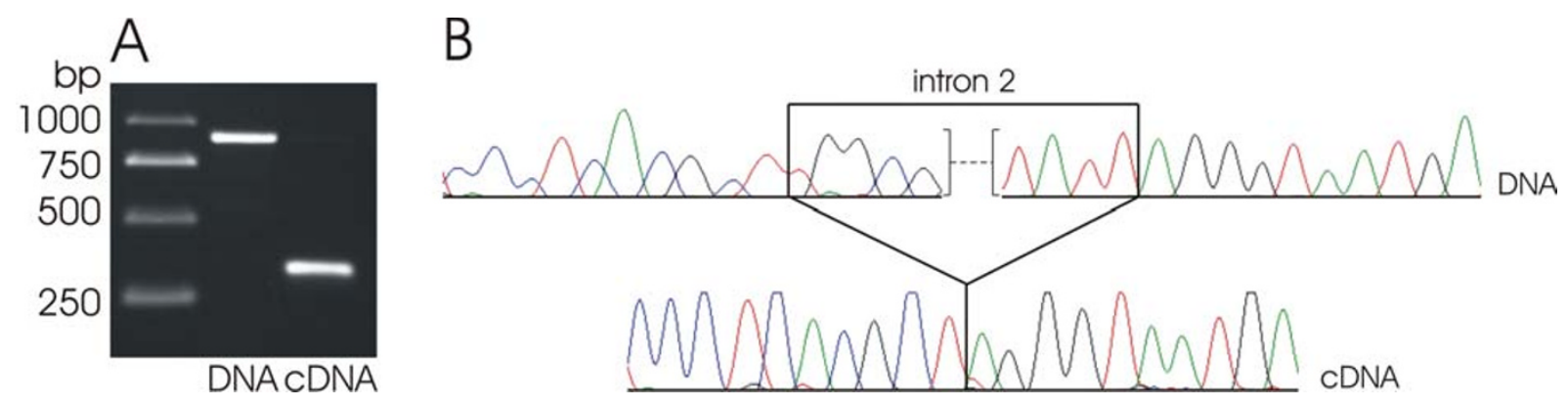

Figure 3

Splicing of the intron 2 of clpP in Cuscuta gronovii. A: PCR (DNA) and RT-PCR (cDNA) products of $c l p P$ overlapping the intron $2 \mathrm{~B}$ : DNA and cDNA sequences of the region around the exon/intron 2 boundaries of $c l p P$

resemble to a high degree those of other parasitic plants [11] so that a facultative adaptation to the parasitic lifestyle has to be proposed. The relative deficiency in change at the genomic level might indicate that this species needs to retain the option of sustaining a host-independent growth for longer periods of time in its natural environment. The high ratio of coding versus non-coding sequence that is characteristic for both Cuscuta species that were investigated (see Table 1), might indicate, that an early reaction of the plastid genome to the parasitic lifestyle is a loss of unused and possibly unimportant noncoding parts of the plastid DNA. This essentially results in a condensation to a smaller, more compact chromosome. As the adaptations to parasitism become more pronounced and manifest themselves in organisms with reduced photosynthetic activity like C. gronovii, some coding regions of the plastid genome, responsible mainly for plastid gene expression, have become affected. Nevertheless, the capacity to synthesize plastid-encoded subunits of the photosynthetic apparatus is still present, demonstrating an evolutionary pressure to retain photosynthesisrelated genes at this stage. It is quite intriguing that the loss of the RNA polymerase genes from the plastid genome, the maturation of the mRNAs and a significant reduction of RNA editing preceded alterations in the components of the photosynthetic apparatus, and might explain the low but nevertheless existent photosynthetic activity of C. gronovii. Thus, a step-by-step reduction in the plastid genome may be characteristic for the genus Cuscuta and perhaps for all parasitic plants. This can range

\section{Cuscuta reflexa}

accD-258 atpF-31 petB-140 petB-204 petL-2 psbE-72 psbL-1 rp/20-103 rps2-45 rps2-83 rps14-27 rps 14-50 rpoB-113 rpoB-158 rpoB-184 rpoB-189 rpoB-667 rpoC1-21

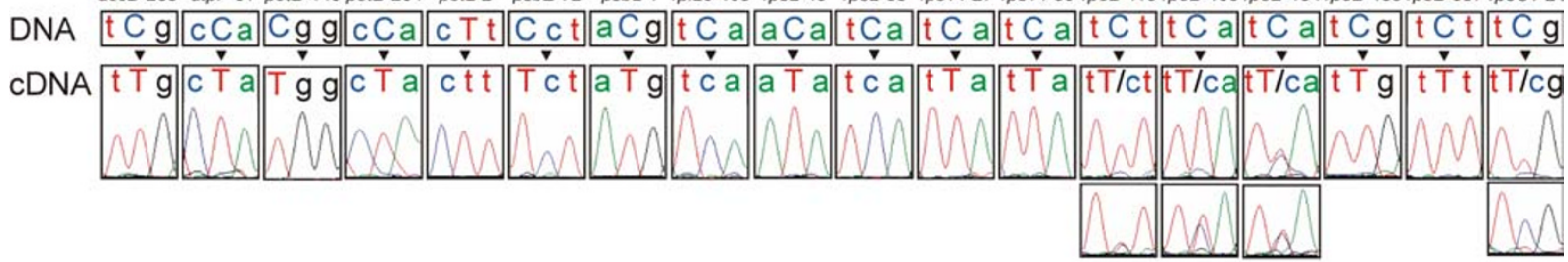

\section{Cuscuta gronovii}

accD-173 atpF-31 petB-140 petB-204 petL-2 psbE-72 psbL-1 rp/20-103 rps2-45 rps2-83 rps14-27 rps14-50

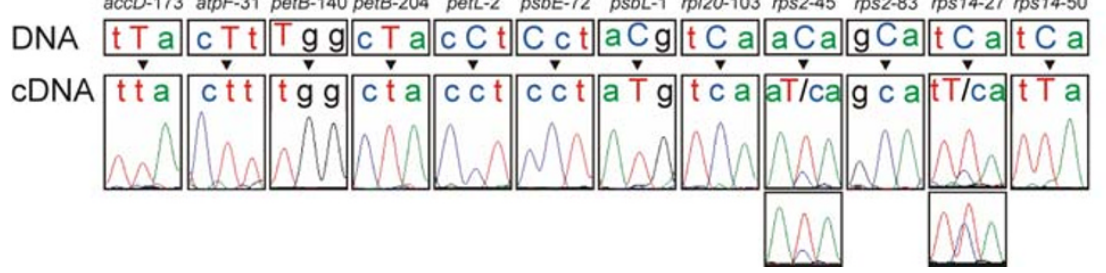

Figure 4

Sequencing chromatogram excerpts of the editing sites in Cuscuta. The uppercase letter indicates the editing site or the conserved amino acid at the DNA level; for partial editing sites two chromatograms are shown in photosynthetic active tissue (top) and in pale tissue (bottom). 
from mild changes in C. reflexa, mainly in the non-coding regions, to massive rearrangements of gene expression in C. gronovii to, finally, the loss of all genes for the photosynthetic apparatus as evidenced in E. virginiana.

\section{Methods}

\section{Plant growth}

C. reflexa and C. gronovii were grown in a greenhouse using Pelargonium zonale as host plant as described by van der Kooij et al. [2] in a light/dark cycle of $16 \mathrm{~h} / 8 \mathrm{~h}$ and day and night temperatures of 22 and $18^{\circ} \mathrm{C}$, respectively.

\section{DNA extraction and sequence analysis}

Total cellular DNA was extracted by a CTAB-based method [57] or with the DNeasy Plant mini Kit (Qiagen, Hilden, Germany). Sequencing of the plastid chromosome of C. reflexa was based on a partial plastid DNA library containing BamHI, HindIII, PstI and PstI/SalI fragments. The gaps between the restriction fragments were closed by PCR using Qiagen Taq Polymerase and for long range PCR the Long PCR Enzyme Mix (Fermentas, St. Leon-Rot, Germany). A long range PCR approach was used for the plastid chromosome of $C$. gronovii. Amplified PCR products were cleaned up by the PCR clean-up Gel extraction Kit NucleoSpin ${ }^{\circledast}$ Extract II (Macherey-Nagel, Dueren, Germany). Clones and cleaned PCR products were directly sequenced using the DYEnamic ET Terminator Cycle Sequencing Kit (GE-Healthcare, Munich, Germany) on an ABI PRISM ${ }^{\circledast} 377$ DNA sequencer (Applied Biosystems, Darmstadt, Germany). All oligonucleotides used for PCR and sequencing were ordered from MWG Biotech (Ebersberg, Germany). Sequences were edited and assembled using the Sequencher 4.6 (Gene Codes Corporation, Ann Arbor, MI, USA). For the identification of the coding open reading frames the ORF finder and blast tools from NCBI were used. tRNAs were identified with the blast tools from NCBI and the tRNAscan-SE 1.21 [58].

\section{Analysis of editing sites}

RNA was isolated by the CTAB-based method also used for DNA isolation [57]. For cDNA synthesis, the RNA was treated with DNase I and reverse transcribed using Omniscript $^{\oplus}$ Reverse Transcriptase or the OneStep RT-PCR Kit (both Qiagen, Hilden, Germany).

\section{Abbreviations}

bp, base pairs; IR, inverted repeat; LSC, large single copy region; NEP, nuclear-encoded plastid RNA polymerase; PEP, plastid-encoded plastid RNA polymerase; ptDNA, plastid DNA; SSC, small single copy region; $\gamma c f$, hypothetical chloroplast reading frame

\section{Authors' contributions}

HTF performed the sequence analysis of the entire $C$. gronovii plastid genome and parts of the $C$. reflexa plastid genome, annotated the C. reflexa and C. gronovii plastid genomes, performed the RT-PCR analysis of transcripts (including the identification of splicing and editing sites), did parts of the promoter analysis together with KiK and was involved in drafting the manuscript. SB performed a large part of the sequence analysis of $C$. reflexa. KaK initiated the project and contributed to the work by the interpretation and discussion of the data. UGM participated in the evaluation and interpretation of the data and significantly contributed to the manuscript by critically reviewing it. KiK designed and coordinated the study, provided the plant material, performed the promoter analysis, and, together with HTF, drafted the manuscript. All authors have read and approved of the final version of the manuscript.

\section{Acknowledgements}

This work was supported in parts by the Deutsche Forschungsgemeinschaft (SFB-TRI). S. Berg received a PhD grant from the Friedrich-Naumann foundation. We thank Christian Schmitz-Linneweber, Michael Tillich and Peter Poltnigg for helpful discussions, Peter Poltnigg also for critical reading of the manuscript and Heidemarie Thierfelder for skilful technical assistance.

\section{References}

I. Hibberd JM, Jeschke WD: Solute flux into parasitic plants. J Exp Bot 200I, 52:2043-2049.

2. van der Kooij TA, Krause K, Dörr I, Krupinska K: Molecular, functional and ultrastructural characterisation of plastids from six species of the parasitic flowering plant genus Cuscuta. Planta 2000, 21 0:701-707.

3. Panda MM, Choudhury NK: Effect of irradiance and nutrients on chlorophyll and carotenoid content and Hill reaction activity in Cuscuta reflexa. Photosynthetica 1992, 26:585-592.

4. Sherman TD, Pettigraw WT, Vaughn K: Structural and immunological characterization of the Cuscuta pentagona L. chloroplast. Plant Cell Physiol 1999, 40:592-603.

5. Haberhausen G, Valentin K, Zetsche K: Organization and sequence of photosynthetic genes from the plastid genome of the holoparasitic flowering plant Cuscuta reflexa. Mol Gen Genet 1992, 232:154-161.

6. Bommer D, Haberhausen G, Zetsche $K$ : A large deletion in the plastid DNA of the holoparasitic flowering plant Cuscuta reflexa concerning two ribosomal proteins (rpl2, rpl23), one transfer RNA (trnl) and an ORF 2280 homologue. Curr Genet 1993, 24:17|-176.

7. Haberhausen $G$, Zetsche $K$ : Functional loss of all ndh genes in an otherwise relatively unaltered plastid genome of the holoparasitic flowering plant Cuscuta reflexa. Plant Mol Biol 1994, 24:217-222.

8. Wimpee CF, Wrobel RL, Garvin DK: A divergent plastid genome in Conopholis americana, an achlorophyllous parasitic plant. Plant Mol Biol 1991, 17:161-166.

9. Thalouarn $P$, Theodet $C$, Russo N, Delavault P: The reduced plastid genome of a non-photosynthetic angiosperm Orobanche hederae has retained the rbcL gene. Plant Physiol Biochem 1994, 32:233-242.

10. Wolfe KH, Morden CW, Palmer JD: Function and evolution of a minimal plastid genome from a nonphotosynthetic parasitic plant. Proc Natl Acad Sci U S A 1992, 89: 10648-10652.

II. Berg S, Krupinska K, Krause K: Plastids of three Cuscuta species differing in plastid coding capacity have a common parasitespecific RNA composition. Planta 2003, 2 18: |35-142. 
12. Revill MJ, Stanley S, Hibberd JM: Plastid genome structure and loss of photosynthetic ability in the parasitic genus Cuscuta. J Exp Bot 2005, 56:2477-2486.

13. Maliga P: Two plastid RNA polymerases of higher plants: an evolving story. Trends Plant Sci 1998, 3:4-6.

14. Hajdukiewicz PT, Allison LA, Maliga P: The two RNA polymerases encoded by the nuclear and the plastid compartments transcribe distinct groups of genes in tobacco plastids. Embo J | 997, 1 6:404|-4048.

I5. Michel F, Umesono K, Ozeki H: Comparative and functional anatomy of group II catalytic introns--a review. Gene 1989 82:5-30.

16. Maier RM, Zeltz P, Kössel H, Bonnard G, Gualberto JM, Grienenberger JM: RNA editing in plant mitochondria and chloroplasts. Plant Mol Biol 1996, 32:343-365.

17. Bock R, Kössel H, Maliga P: Introduction of a heterologous editing site into the tobacco plastid genome: the lack of RNA editing leads to a mutant phenotype. Embo J 1994 1 3:4623-4628.

18. Hirose T, Sugiura M: Both RNA editing and RNA cleavage are required for translation of tobacco chloroplast ndhD mRNA: a possible regulatory mechanism for the expression of a chloroplast operon consisting of functionally unrelated genes. Embo J 1997, 16:6804-68II.

19. Schmitz-Linneweber C, Kushnir S, Babiychuk E, Poltnigg P, Herrmann RG, Maier RM: Pigment deficiency in nightshade/tobacco cybrids is caused by the failure to edit the plastid ATPase alpha-subunit mRNA. Plant Cell 2005, I 7:|8| 5-1828.

20. Sasaki Y, Kozaki A, Ohmori A, Iguchi H, Nagano Y: Chloroplast RNA editing required for functional acetyl-CoA carboxylase in plants. I Biol Chem 200I, 276:3937-3940.

21. Zito F, Kuras R, Choquet Y, Kössel H, Wollman FA: Mutations of cytochrome b6 in Chlamydomonas reinhardtii disclose the functional significance for a proline to leucine conversion by petB editing in maize and tobacco. Plant Mol Biol I997, 33:79-86.

22. Funk HT, Poltnigg P, Schmitz-Linneweber C, Tillich M: Transcript polishing in higher plant plastids by RNA editing. Endocytobiosis and Cell Res 2004, 1 5:491-503.

23. Freyer R, Kiefer-Meyer MC, Kossel H: Occurrence of plastid RNA editing in all major lineages of land plants. Proc Natl Acad Sci $U$ S A 1997, 94:6285-6290.

24. Cui L, Veeraraghavan N, Richter A, Wall K, Jansen RK, Leebens-Mack J, Makalowska I, dePamphilis CW: ChloroplastDB: the Chloroplast Genome Database. Nucleic Acids Res 2006, 34:D692-6.

25. Ems SC, Morden CW, Dixon CK, Wolfe KH, dePamphilis CW Palmer JD: Transcription, splicing and editing of plastid RNAs in the nonphotosynthetic plant Epifagus virginiana. Plant $\mathrm{Mol}$ Biol 1995, 29:72|-733.

26. Shinozaki K, Ohme M, Tanaka M, Wakasugi T, Hayashida N, Matsubayashi T, Zaita N, Chunwongse J, Obokata J, Yamaguchi-Shinozaki K, Ohto C, Torazawa K, Meng BY, Sugita M, Deno H, Kamogashira T, Yamada K, Kusuda J, Takaiwa F, Kato A, Tohdoh N, Shimada H, Sugiura $M$ : The complete nucleotide sequence of the tobacco chloroplast genome: its gene organization and expression. Embo J 1986, 5:2043-2049.

27. Wakasugi T, Sugiura M, Tsudzuki T, Sugiura M: Updated Gene Map of Tobacco Chloroplast DNA. Plant Molecular Biology Reporter |998, | 6:23|-24|

28. Stefanovic S, Olmstead RG: Down the slippery slope: plastid genome evolution in Convolvulaceae. I Mol Evol 2005, 61:292-305.

29. Pfitzinger $\mathrm{H}$, Weil JH, Pillay DT, Guillemaut $\mathrm{P}$ : Codon recognition mechanisms in plant chloroplasts. Plant Mol Biol 1990, | 4:805-8|4

30. Barbrook AC, Howe CJ, Purton S: Why are plastid genomes retained in non-photosynthetic organisms? Trends Plant SC 2006, II:101-108.

31. Wolfe KH, Morden CW, Ems SC, Palmer JD: Rapid evolution of the plastid translational apparatus in a nonphotosynthetic plant: loss or accelerated sequence evolution of tRNA and ribosomal protein genes. J Mol Evol 1992, 35:304-317.

32. Bhattacharyya SN, Adhya S: The complexity of mitochondrial tRNA import. RNA Biol 2004, I:84-88.

33. Lohan AJ, Wolfe $\mathrm{KH}$ : A subset of conserved tRNA genes in plastid DNA of nongreen plants. Genetics 1998, I50:425-433.
34. Wakasugi T, Tsudzuki J, Ito S, Nakashima K, Tsudzuki T, Sugiura M: Loss of all ndh genes as determined by sequencing the entire chloroplast genome of the black pine Pinus thunbergii. Proc Natl Acad Sci U S A 1994, 91 :9794-9798.

35. Downie SR, Palmer JD: Use of chloroplast DNA rearrangements in reconstructing plant phylogeny. Soltis PS, Soltis DE, Doyle JJ (eds) Molecular systematics of plants Chapman and Hall, New York 1992.

36. Ohyama K, Fukuzawa H, Kohchi T, Shirai H, Sano T, Sano S, Umesono K, Shiki Y, Takeuchi M, Chang Z, Aota S, Inokuchi H, Ozeki H: Chloroplast gene organization deduced from complete nucleotide sequence of liverwort Marchantia plolymopha chloroplast DNA. Nature 1986, 322:572-574.

37. Zurawski G, Clegg MT: Evolution of higher-plant chloroplast DNA-encoded genes: implications for structure-function and phylogenetic studies. Ann Rev Plant Physiol 1987, 38:.

38. Krause K, Berg S, Krupinska K: Plastid transcription in the holoparasitic plant genus Cuscuta: parallel loss of the rrn I6 PEP-promoter and of the rpoA and rpoB genes coding for the plastid-encoded RNA polymerase. Planta 2003, 21 6:815-823

39. Delavault P, Thalouarn P: Plastid genome evolution in Orobanchaceae and other holoparasites. Pieterse, $A H$, Verkleij, JAC and ter Borg, SJ (Eds), Proceedings of the 3rd International Workshop on Orobanche and related Striga research Amsterdam, The Netherlands 1994.

40. Morden CW, Wolfe KH, dePamphilis CW, Palmer JD: Plastid translation and transcription genes in a non-photosynthetic plant: intact, missing and pseudo genes. Embo J I99|, I 0:328|-3288.

41. Wimpee CF, Morgan R, Wrobel RL: Loss of transfer RNA genes from the plastid I6S-23S ribosomal RNA gene spacer in a parasitic plant. Curr Genet 1992, 2 I:417-422.

42. Berg S, Krause K, Krupinska K: The rbcL genes of two Cuscuta species, $C$. gronovii and $C$. subinclusa, are transcribed by the nuclear-encoded plastid RNA polymerase (NEP). Planta 2004, 219:54I-546.

43. Shiina T, Tsunoyama Y, Nakahira Y, Khan MS: Plastid RNA polymerases, promoters, and transcription regulators in higher plants. Int Rev Cytol 2005, 244: I-68.

44. Christopher DA, Mullet JE: Separate photosensory pathways coregulate blue light/ultraviolet-A-activated psbD-psbC transcription and light-induced D2 and CP43 degradation in barley (Hordeum vulgare) chloroplasts. Plant Physiol 1994, 104:1119-1129.

45. Nagashima A, Hanaoka M, Shikanai T, Fujiwara M, Kanamaru K, Takahashi $\mathrm{H}$, Tanaka $\mathrm{K}$ : The multiple-stress responsive plastid sigma factor, SIG5, directs activation of the psbD blue lightresponsive promoter (BLRP) in Arabidopsis thaliana. Plant Cell Physiol 2004, 45:357-368.

46. Meng BY, Wakasugi T, Sugiura M: Two promoters within the psbK-psbl-trnG gene cluster in tobacco chloroplast DNA. Curr Genet 1991, 20:259-264.

47. Chen MC, Cheng MC, Chen SC: Characterization of the promoter of rice plastid psaA-psaB-rps 14 operon and the DNAspecific binding proteins. Plant Cell Physiol 1993, 34:577-584.

48. Kapoor S, Wakasugi T, Deno H, Sugiura M: An atpE-specific promoter within the coding region of the atpB gene in tobacco chloroplast DNA. Curr Genet 1994, 26:263-268.

49. Allen JF, Pfannschmidt T: Balancing the two photosystems: photosynthetic electron transfer governs transcription of reaction centre genes in chloroplasts. Philos Trans $R$ Soc Lond B Biol Sci 2000, 355:1351-1359.

50. Vogel J, Hübschmann T, Börner T, Hess WR: Splicing and introninternal RNA editing of trnK-matK transcripts in barley plastids: support for MatK as an essential splice factor. I Mol Biol 1997, 270:179-187.

5I. Liere K, Link G: RNA-binding activity of the matK protein encoded by the chloroplast trnK intron from mustard (Sinapis alba L.). Nucleic Acids Res 1995, 23:917-921.

52. Hess WR, Hoch B, Zeltz P, Hübschmann T, Kössel H, Börner T: Inefficient rpl2 splicing in barley mutants with ribosome-deficient plastids. Plant Cell 1994, 6: | 455- I465.

53. Hubschmann T, Hess WR, Börner T: Impaired splicing of the rps 12 transcript in ribosome-deficient plastids. Plant $\mathrm{Mol}$ Biol 1996, 30:109-123.

54. Jenkins BD, Kulhanek DJ, Barkan A: Nuclear mutations that block group II RNA splicing in maize chloroplasts reveal several 
intron classes with distinct requirements for splicing factors. Plant Cell 1997, 9:283-296.

55. Hattori M, Miyake H, Sugita M: A Pentatricopeptide repeat protein is required for RNA processing of clpP Pre-mRNA in moss chloroplasts. J Biol Chem 2007, 282: 10773-10782.

56. Vogel J, Börner T, Hess WR: Comparative analysis of splicing of the complete set of chloroplast group II introns in three higher plant mutants. Nucleic Acids Res 1999, 27:3866-3874.

57. Doyle J, Doyle L: Isolation of plant DNA from fresh tissue. Focus 1990, 12:.

58. tRNAscan-SEI.21: [http://lowelab.ucsc.edu/tRNAscan-SE].

Publish with Bio Med Central and every scientist can read your work free of charge

"BioMed Central will be the most significant development for disseminating the results of biomedical research in our lifetime. "

Sir Paul Nurse, Cancer Research UK

Your research papers will be:

- available free of charge to the entire biomedical community

- peer reviewed and published immediately upon acceptance

- cited in PubMed and archived on PubMed Central

- yours - you keep the copyright

Submit your manuscript here:

http://www.biomedcentral.com/info/publishing_adv.asp
BioMedcentral 